\title{
Modularizing services based upon an actor-oriented logic
}

\begin{abstract}
The present research investigates how actor-oriented service modularity (here, decomposing services in packages delivered by single versus multiple service providing entities) impacts the formation of customer experiences in relation to the focal service provider (i.e., the service provider engaged in modularizing services). To test our hypotheses in the context of cancer care, patient observations $(n=640)$ and a patient survey $(n=377)$ were used to gather respectively service package and customer experience data. These data were analyzed using hierarchical Bayes models. Our results show that customer experiences with the focal service provider are shaped by waiting time, interactional and environmental quality in case of single service provider packages. Multiple service provider packages, in turn, divert customers' attention from waiting time and interactional quality with the focal service provider, but not from environmental quality. A notable exception involves multiple service provider packages with high time and location proximity, since none of the experience drivers affect customer experiences with the focal service provider. By proposing a new logic for service modularity (i.e., actor-oriented logic) and investigating its implications for the customer experience formation in relation to the focal service provider, this research contributes to the service design and modularity literature.
\end{abstract}

\section{Keywords:}

service modularity; customer experience; service design 


\section{INTRODUCTION}

Customization has become a key concern when designing service delivery processes, as customized service delivery processes are supposed to generate better customer experiences by flexibly attending to customer needs (Tuunanen et al., 2012). To ensure that customization efforts bring not only customer experience benefits but also efficiency gains for service providers, an increasing number of researchers and practitioners have resorted to service modularity. Although

a multitude of definitions exist, service modularity is in essence a way to design services so that customized service packages can be created for individual customers from distinct components, where components reflect the smallest parts that a service can be meaningfully divided into (Pekkarinen and Ulkuniemi 2008; Peters et al., 2018).

The present research proposes an actor-oriented logic (i.e., decomposing services into the actors involved - see Figure 1) for combining service components into packages. So far, the service modularity literature revealed two approaches for combining components into service packages, namely combining components based upon what service is delivered (cf. outcome-oriented logic) and how service is delivered (cf. process-oriented logic) (Eissens-van der Laan et al., 2016). The outcome-oriented logic relates to decomposing services into small deliverables to the client, while a process-oriented logic decomposes services into its constituting activities (Eissens-van der Laan et al., 2016). Extant research suggests that customers expect freedom of choice in terms of not only what services are delivered (e.g., core versus value-added) and how services are delivered (e.g., pre-payment versus post-payment), but also who is involved in the delivery of services (Tax et al., 2013; Brax et al., 2017). Therefore, this study builds upon an actor-oriented logic for combining service components into packages. Service providers, for instance, can create service packages where all service components are delivered by the same service provider (single service provider 
packages) versus those where two or more service providing entities produce service components (multiple service provider packages). In other words, actor-oriented service modularity represents an approach where packaging is based on the service providing actors involved in the delivery of service.

This research aims to provide insight into how actor-oriented service packages - here, single and multiple service provider packages - affect customer experience formation in relation to the focal service provider, where the focal service provider involves the service provider engaged in modularizing services in an actor-oriented way and customer experience formation refers to generation of customer experiences in relation to the focal service provider. Specifically, customer experience formation in relation to the focal service provider encompasses the overall experience with the focal service providers and three drivers that are - at least to a large extent controlled by the focal service provider: waiting time (the actual time spent waiting for the service components offered by the focal service provider), environmental quality (the quality of the physical environment in which the service components of the focal service provider are offered), and interactional quality (the quality of the interactions with employees involved in the delivery of service components associated with the focal service provider).

By focusing on the implications of actor-oriented packages on customer experience formation in relation to the focal service provider, this research contributes to the service design and modularity literature in two important ways. First, the aforementioned literature streams are advanced by proposing a new logic for service modularity (i.e., actor-oriented logic), thereby extending the number of design choices for service providers. Second, by empirically investigating the implications of these design choices for customer experience formation in relation to the focal service provider, this research responds to calls for research on performance effects in the context of service delivery system design (e.g., Zomerdijk and de Vries, 2007; Ponsignon et al., 2011; 
Wikner et al., 2017) and service modularity in a multi-provider context (e.g., Brax et al., 2017; Avlonitis and Hsuan, 2017). From a managerial perspective, this research helps service providers to modularize services and/or (re-)design service delivery processes for generating better customer experiences, which is important to compete and retain customers in case of competing but undifferentiated services (Beltagui et al., 2016).

This paper proceeds as follows. The first section provides a conceptual model describing how actor-oriented service modularity affects the formation of customer experiences in relation to focal service providers. In the next section, we detail the empirical study in the context of cancer care based upon a combination of patient observations and patient survey data, followed by the results of our (post-hoc) analyses. We conclude with the theoretical contribution, the limitations and future research directions along with the managerial implications.

\section{CONCEPTUAL FRAMEWORK}

\section{Designing services for generating better customer experiences}

Starting point for this research is that service providers cannot design the customer experience, but the service can be designed for generating better customer experiences (Patrício et al., 2011). In other words, customer experience formation - i.e., the way in which customer experiences are generated - is likely to be affected by service design (Avlonitis and Hsuan, 2017; Verleye, 2015). Traditionally, service design relates to (1) the service concept: what services are delivered, (2) the service delivery system: how services are delivered, and (3) the targeted market: who is the right customer, which constitute the service strategy triad (Roth and Menor, 2003; Ponsignon et al., 2011). In more recent years, researchers have proposed to customize the service concept and the service delivery system in a more efficient way by introducing service modularity (Pekkarinen and Ulkuniemi, 2008; Eissens-van der Laan et al., 2016; Peters et al., 2018). Here, 
service modularity refers to designing services so that customized service packages can be created for individual customer from distinct components, which are the smallest parts that a service can be meaningfully divided into (De Blok et al., 2014; Eissens-van der Laan et al., 2016). Specifically, the service modularity literature is based on two logics for decomposing services into components, more particularly an outcome-oriented logic and a process-oriented logic (Eissens-van der Laan et al., 2016). When an outcome-oriented logic is applied, services are decomposed based upon the service components offered (what services are delivered). A process-oriented logic, in turn, decomposes services based upon the sequence in which service components are provided (how services are delivered). Unlike previous service modularity research, this research proposes a third logic for decomposing services to generate better experiences in an efficient way: an actor-oriented logic where services are decomposed based upon the actors involved in producing service components (see Figure 1).

Insert Figure 1 about here

An actor-oriented logic for modularizing services is important, as service providers increasingly allow customers to involve service providers of their own choice for the delivery of specific service components (Tax et al., 2013; Lemon and Verhoef, 2016). To ensure that this form of customization also generates efficiency gains, the focal service provider can modularize its services by decomposing services based upon the service providing actors involved in the delivery of the service components. Surprisingly, this actor-oriented service modularity logic has received limited attention. A notable exception is De Blok et al. (2014) who study services decomposed based upon what service are provided (outcome-oriented logic), but recognize that not all services can be provided by the same service provider. Clients who opt for a service package combining cleaning and catering services might encounter other service providers than those who opt for a 
service package with housing, cleaning services but no catering services. Brax et al. (2017) go a step further by calling for further investigation of modularizing services in a multi-provider context. Despite the acknowledgement of multi-provider contexts, extant research suggests that not all customers desire service packages where multiple service providers produce service components (multiple service provider package). To generate better experiences for customers who want to reduce the number of service providers, McColl-Kennedy et al. (2012) point out that service providers may still offer service packages where all service components are provided by the focal service provider (single service provider package).

Although offering both single and multiple service provider packages might affect customer experience formation, the implications of this type of actor-oriented service modularity have not been investigated. This research investigates the impact of this type of actor-oriented service modularity on customer experience formation in relation to the focal service provider (i.e., the service provider engaged in modularizing services and producing at least one of the service components). In other words, this research centers on (1) a specific type of actor-oriented service modularity (i.e., offering a choice between single and multiple service provider packages), and (2) the impact of these actor-oriented service packages on customer experience formation in relation to the focal service provider. By focusing on customer experience formation in relation to the focal service provider (instead of customer experience formation in general), this research aims to help service providers to achieve competitive advantages in a multi-provider context. Extant research suggests that service providers merely compete with one another based upon the waiting time and other service quality attributes (Allon and Federgruen, 2007; Bitran et al., 2008), as these customer experience drivers are controlled by the service provider (Lemon and Verhoef, 2016). Previous studies have shown that waiting time does not only have an important impact on customer experience formation in relation to the focal service provider, but can also be managed by the focal 
service provider (Pruyn and Smidts, 1998). Meanwhile, the experience literature points to the importance of the environment in which the service is delivered, in that better environmental quality - which is created by a good atmosphere and relevant tangibles - can be managed and generates better customer experiences (Voorhees et al., 2009). Additionally, the customer experience formation also depends on the quality of the interactions with service employees (Dagger et al., 2007).

Based upon the importance of waiting, environmental quality, and interactional quality for the customer experience formation in relation to the focal service provider, the next section hypothesizes about how the customer experience formation in relation to the focal service provider is affected by actor-oriented service package choices (here, single versus multiple service provider package).

\section{Waiting and customer experience formation}

Several researchers consider waiting as an important aspect of customer experience formation (Lemke et al., 2011; Weiss and Tucker, 2018). It has long been recognized, however, that waiting has an objective and subjective facet. We define the objective waiting time - in line with previous research (Durrande-Moreau and Usunier, 1999) - as the actual time spent waiting for the delivery of the service measured by the objective clock time. In contrast, the subjective waiting time refers to customer perceptions of the actual waiting time, which encompasses not only the average perceived waiting time but also customers' perceptions of the cognitive evaluation of the waiting time (time was long versus short) and affective evaluation of the waiting time (the waiting time was dissatisfactory versus satisfactory) (Pruyn and Smidts, 1998).

To date, several studies support the argument that shorter waiting times lead to better overall experiences. For instance, extant evidence shows a negative relationship between the actual waiting 
time and the perceived service quality and/or satisfaction with the service (Taylor, 1994; Kumar and Krishnamurthy, 2008). Other studies consistently show a negative relationship between customers' perceptions of the actual waiting time - i.e., the cognitive and affective waiting time evaluation - and service quality and satisfaction (e.g., Van Riel et al., 2012). Also several studies conclude and empirically demonstrate that the relationship between the actual waiting time and the evaluation of the service experience is mediated by the waiting experience (i.e., the cognitive and affective facet of waiting time evaluation) (e.g., Pruyn and Smidts, 1998). Based upon this evidence, we argue that shorter waiting times lead - either directly or indirectly through better waiting experiences - to better overall experiences with the focal service provider if a single service provider package is chosen. The question, however, revolves around the impact of choosing a multiple service provider package on the relationships between waiting time and customers' evaluations of their experiences in relation to the focal service provider.

Drawing from attribution theory (Heider, 1958), several researchers suggest that the evaluation of the customer experiences - including their experiences related to waiting - depend on how customers explain events (Albrecht et al., 2016). Indeed, the degree to which service providers are perceived to have control over the time needed to deliver the service affects the evaluation of the customer experience (Taylor, 1994; Albrecht et al., 2016). Customers who experience a long wait in case of a delayed flight, for instance, may infer a wide variety of causes beyond control of the focal service provider, such as bad weather, a mechanical breakdown, or problems with respect to air traffic control (Van Vaerenbergh et al., 2014). Building upon attribution theory, the involvement of multiple service providing entities may increase the likelihood of attributing waiting to causes beyond control of the focal service provider even more, because customers gain more insight into causes of waiting beyond control of the service provider. As such, the negative implications for the formation of the customer experience in relation to the 
focal service provider are reduced. Moreover, the delivery of services by other providers than the focal service provider may - in line with the psychology of waiting lines (Maister, 1984) - also distract customers' attention from the actual waiting time to get the core service from the focal service provider (Van Riel et al., 2012, Lim et al., 2015). Based upon the aforementioned arguments, we hypothesize:

Hypothesis 1: The positive impact of shorter waiting times on the evaluation of the overall experience with the focal service provider, either directly or indirectly through better evaluations of the waiting experience, is weakened if a multiple service provider package - as opposed to a single service provider package - is chosen.

\section{Customer experience drivers beyond the actual waiting time}

Extant research suggests that the customer experience formation in relation to the focal service provider - which are also reflected in the perceived service quality and satisfaction - does not exclusively depend on the efficiency of service delivery processes, as directly reflected in the actual waiting time and indirectly in the waiting experiences (Dagger et al., 2007; Lemke et al., 2011). On the contrary, conceptual work of Baker and Cameron (1996) suggests that physical and social elements in the service environment also affect the overall experience with the focal service provider. Moreover, customer experience is even defined as the outcome of interactions with physical and social elements during service provision and consumption (Pullman and Gross, 2004). Indeed, the quality of the physical environment in which the service delivery takes place - i.e., environmental quality - and the quality of the interactions with employees - i.e., interactional quality - have long been recognized as important aspects of the customer experience (Dagger et al., 2007; Kranzbühler et al., 2018). 
Moreover, environmental and interactional quality associated with the focal service provider are not only important customer experience drivers, but may even have a significant impact on the waiting experience by acting respectively as 'distractors' or 'fillers'. Over the past few years, empirical studies have shown that the environmental quality can improve customers' appraisal of wait by distracting customers' attention from the wait (e.g., Voorhees et al., 2009). The interactional quality in the service environment, in turn, was found to affect customers' appraisal of wait, in that social interaction fills time (Lim et al., 2015). This evidence is in line with the psychology of waiting lines, which holds that occupied time feels shorter than unoccupied time (Maister, 1984; Taylor, 1994). Therefore, we conclude that environmental quality and interactional quality have a positive impact - directly and indirectly through better waiting experiences - on the overall experience with the focal service provider if a single service provider package is chosen. Here again, however, the question raises how choosing a multiple service provider package affects the aforementioned relationships.

We argue that the impact of environmental and interactional quality on the overall experience with the focal service provider is influenced by the other service providing entities. Previous research has shown that customers tend to rely on competitive comparisons/norms when evaluating their consumption experience, which implies that competitors serve as benchmark to evaluate the experience with the focal firm (Gardial et al., 1994). Information integration theory also holds that individuals repetitively use newly accessed stimuli from the environment to continually update attitudes and beliefs (Anderson, 1981). Thus, when the new stimuli - such as services of providers other than the focal service provider - are processed, this information directly influences individuals' processing of new information (Simonin and Ruth, 1998). More recently, researchers have shown that the evaluation of the customer experience in relation to a specific service provider are influenced by their experiences with other service providers, in that negative 
experiences with other service providers may spill over to their experience with the focal provider (Allen et al., 2015). The aforementioned theorizing suggests that the impact of different customer experience drivers in relation to the focal service providers may weaken, in that experiences of other service provider entities may also affect and hence explain the experience formation in relation to the focal service provider. In other words, other service providing entities may deduce customers' attention away from the interactional and environmental quality associated with the focal service provider. Based upon the aforementioned arguments, we hypothesize:

Hypothesis 2a: the positive impact of environmental quality on the evaluation of the overall experience with the focal service provider, either directly or indirectly through better evaluations of the waiting experience, is weakened if a multiple service provider package - as opposed to a single service provider package - is chosen.

Hypothesis $2 \boldsymbol{b}$ : the positive impact of interactional quality on the evaluation of the overall experience with the focal service provider, either directly or indirectly through better evaluations of the waiting experience, is weakened if a multiple service provider package - as opposed to a single service provider package - is chosen.

\section{METHODOLOGY}

\section{Research setting and data collection}

The setting for this research is the healthcare context. The healthcare context is characterized by complex service delivery systems related to complex patient needs (Berry and Bendapudi, 2007). Specifically, this study centers on patients undergoing cancer treatment. To investigate the implications of actor-oriented service packages for the formation of the customer 
experience in relation to the focal service provider, we relied on data about cancer patients treated in two cancer daycare units (CDUs) associated with one of the largest hospitals in Belgium. The CDUs have implemented a multiple service provider package to allow patients to involve service providers of their own choice outside the CDU while also creating more available service capacity for their core business, i.e. chemotherapy. A single service provider package was offered to meet the needs of patients that did not prefer - due to medical or personal reasons - multiple service providers. To gain insight into the actor-oriented service packages (i.e. a single and multiple service provider package), a document analysis focusing on formal process descriptions, planning tools, and documentation from a former (re-)design project in the CDU was performed. Next, six semistructured interviews were carried out to gain more insight into the actor-oriented service packages. The document analysis and semi-structured interviews revealed that patients are - depending on their type of health problem - free to engage with either the CDU or other service providers for the delivery of one or more of the following three service components: blood sample, physician consult and a test of the patient's condition. In other words, different service components can be delivered by either the focal service provider (here, the CDUs) or other service providers (here, general practitioners, polyclinics and other healthcare professionals).

To investigate the impact of single and multiple service provider packages on the formation of the customer experience in relation to the focal service provider, we combined data gathered by means of a patient observation template with patient survey data. Each of these types of data is detailed below. Approval from an ethical committee was obtained for the data collection procedure and all patients gave informed consent before filling out the questionnaire. In total, 780 patient observation templates and patient surveys were distributed at the CDUs, whereof 640 usable patient observation templates $(82.1 \%$ response rate) and 487 usable questionnaires were returned $(62.4 \%$ 
response rate). After linking the questionnaires to the patient observations, we obtained a sample of 377 cancer patients.

\section{Patient observations}

Patients observations were used to capture the type of actor-oriented service package (single versus multiple service provider package) along with the waiting time for service components produced at the CDU (waiting time). The delivery of different service components in single and multiple service packages was documented by means of a patient observation template (see Table 1 for an overview of the way in which these data were coded and/or calculated). Specifically, patient observation templates were filled out for each individual patient by nurses at the CDU. The nurses registered all service components related to the delivery of cancer daycare at the CDU along with those provided by other service providing entities in case of multiple service provider packages. These data confirm that the CDU is always engaged in the delivery of at least one of the service components while other service providers can be engaged in the delivery of blood samples, physician consults and patient condition.

Based upon time stamps associated with the delivery of the different service components in the patient observation template (e.g., patient registration, blood sample, cancer therapy), we were able to capture the time between the start of the delivery of the first service component at the CDU and the start of the delivery of the last service component at the CDU in minutes. As the distribution of waiting time is skewed, a log transformation was performed. In line with Hypothesis 1, waiting time was reversed (1/Waiting time) so that a higher score reflects a shorter waiting time.

Time stamps associated with the delivery of service components also provided insight into the number of components delivered at the CDU after patients' arrival, which can deduce the attention away from the waiting time at the CDU (Maister, 1984). Therefore, the number of CDU 
components was included as a control variable. Additionally, we controlled for the CDU in which the patient was treated, as two CDUs were involved in this research. Next, the presence of fellow customers was taken into consideration, because fellow customers may have an impact on the patient experience that is not under control of the focal service provider (Verleye et al., 2014). Finally, the treatment response - whether or not negative side effects occurred during treatment was considered, in that this may affect the waiting time experience (Carr et al., 2014) and the patient experience (Clucas, 2016).

Insert Table 1 about here

\section{Patient survey}

To capture the waiting experience, the environmental quality, the interactional quality, and the overall experience in relation to the CDU, we gathered patient survey data. The waiting experience, the environmental quality, and the interactional quality were measured by previously validated scales scored on seven-point scales ranging from "strongly disagree" to "strongly agree". With regard to the waiting experience, we included three items from Hui and Tse (1996), which captured the cognitive facet of the wait (i.e., the perceived length and unacceptability of the wait) and the affective facets of the wait (i.e., the irritation associated with the wait based on the interpretation process). The scores on these items were reversed to capture the waiting experience in which higher scores reflect better experiences. The environmental quality was measured by a three-item scale of Dagger et al. (2007). To capture the interactional quality, we used - in line with Dagger et al. (2007) - the nine-item scale for interactional quality. The evaluation of the overall experience in relation to the focal service provider (i.e., the CDU) is captured by the four-item overall experience scale (Verleye, 2015). Finally, we also controlled for age and employment 
situation in the patient survey, in that these variables were found to influence the waiting experience (Patterson et al., 2017) and the overall experience of cancer patients (Clucas, 2016).

As recommended by Netemeyer et al. (2003), we conducted an exploratory factor analysis and an initial item and reliability analysis to identify items with cross-loadings and items that were poorly correlated with the remaining items in each scale. No poorly correlating items were identified. A principal axis factoring (oblique rotation) extracted four factors with eigenvalues greater than one. Additionally, a Harmon's single-factor test using exploratory factor analysis was conducted to check whether a single factor emerged or one general factor accounted for the majority of the covariance among the measures. The first factor accounted for $30.4 \%$ of the variance and all factors together explained $74.6 \%$ of the variance. Consequently, none of these factors accounted thus for the majority of the covariance among the items, as a result of which common method bias was not a serious threat to our analyses (Podsakoff et al., 2003).

Finally, the validity of the constructs was assessed using confirmatory factor analysis (CFA; LISREL 8.50). The measurement model for the sample performed well. Firstly, the ratios of chisquare to degrees of freedom, $\chi 2(553.07) / \mathrm{df}(199)=2.78$ for the sample, are less than three, which is recommended by Netemeyer et al., 2003. Secondly, the comparative fit index (CFI), .96, and Tucker-Lewis index (TLI), .96, were all above common benchmarks of .90. Finally, the root mean square error of approximation (RMSEA) was .07, which represents an acceptable fit (Netemeyer et al., 2003). Table 2 shows the individual items and item loadings. The sample showed convergent validity, because almost all construct reliabilities $(\mathrm{CR})$ were greater than .60 , which is considered a desirable construct reliability and all average variances extracted (AVE) exceeded .50 (see Table 2). In the meanwhile, there is evidence for discriminant validity (see Table 2), since the square root of the AVE for all constructs exceeded the factor correlations (Fornell and Larcker, 1981). Since the measurement model performed well, we used mean scores for the waiting experience, the 
environmental quality, the interactional quality, and the overall experience in relation to the CDU for further analyses.

Insert Table 2 about here

\section{Data analysis procedure}

To understand the impact of single versus multiple service providers packages on the customer experience formation in relation to the focal service provider, a hierarchical Bayes model is used in which all dependent variables are simultaneously modeled and correlated errors between dependent variables are accounted for (Keiningham et al., 2018). For this study, we relied on customer's service package choice data (i.e., single versus multiple service provider package). As such, customers were not randomly assigned to a specific condition in terms of service packages. This study controls for customer heterogeneity by means of six variables: age, employment situation, CDU, service components offered by the CDU, fellow customer, and treatment response. Two ad hoc analyses revealed that the customer's service package choice can be explained by these six control variables. Specifically, a binary logistic regression model with single versus multiple service provider package as dependent variable and the six aforementioned control variables as independent variables revealed a $80.4 \%$ prediction accuracy (Nagelkerke $\mathrm{R}^{2}=59 \%$ ). Since we control for these six variables in our model, the customer's service package choice can be considered to have random differences. As such, case selection bias is not a confounding factor in our analysis (Ho et al., 2017).

\section{RESULTS}

The waiting time - displayed in minutes - varied a lot among cancer patients (mean=94.16; $\mathrm{SD}=68.17$ ). The maximum waiting time is 375 minutes, but patient observations also revealed a situation without any waiting time (i.e., a patient who received his treatment upon arrival at the 
CDU). At the CDU, the large majority of patients was engaged in three to four components at the CDU (84.4\%) and few patients had a chance to engage with fellow customers at the CDU (17.2\%). Half of the patients were younger than $60(49.6 \%)$ and more than half of the patients were still employed (53.3\%). Interestingly, one third of the patients chose a multi-provider service package $(33.4 \%)$.

To assess the impact of customer experience drivers on overall experience, we used a mediation approach with Bayesian estimation (Yuan and MacKinnon, 2009) for two reasons. First, the Bayesian approach does not impose restrictive normality assumptions on sampling distributions of estimates, thereby making statistical inferences straightforward and exact (Yuan and MacKinnon, 2009). Second, Bayesian estimation is particularly valid in smaller samples (Hox et al., 2010). We ran three independent MCMC chains with different starting points and 10,000 iterations each, by which the first half is considered as the "burn-in" phase and the remaining half is used to estimate the posterior distribution for the parameters. To assess the convergence of the MCMC algorithm, we inspected the Gelman-Rubin convergence statistic R, autocorrelation plots, and trace plots of the residual variance for the parameter estimates.

As suggested by Yuan and MacKinnon (2009), the following two equations were jointly estimated using path modeling:

$$
\begin{gathered}
W X_{i m}=X_{i} \mathrm{a}_{\mathrm{m}}+C_{i} \mathrm{j}_{\mathrm{m}}+\mathrm{e}_{\mathrm{im}}(1) \\
O X_{i m}=X_{i} \mathrm{~g}_{\mathrm{m}}+C_{i} \mathrm{~h}_{\mathrm{m}}+W X_{i} b_{m}+\mathrm{q}_{\mathrm{im}}(2)
\end{gathered}
$$

in which $\mathrm{e}_{\mathrm{im}}$ and $\mathrm{q}_{\mathrm{im}}$ are the error terms with intercorrelation $r$ and $W X_{\text {in }}$ and $O X_{\text {in }}$ denote respectively the waiting experience and the overall experience for individual $i$. In total, three models $(m)$ are run: the first model $(m=1$; Model 1 hereafter) represents a baseline model that disregards the choice of an actor-oriented service package, whereas the remaining models provide insights into the parameter estimates for single provider service packages $(m=2$, Model 2 hereafter) and multiple 
provider service packages ( $m=3$, Model 3 hereafter). $X_{i}$ is a vector of the key antecedent constructs and includes waiting time, environmental quality and interactional quality. $\mathrm{C}_{\mathrm{i}}$ is a vector of the control variables. As mentioned before, in this study, we control for age, employment situation, treatment response, $\mathrm{CDU}$, number of service components delivered by the $\mathrm{CDU}$, and presence of a fellow customer. $a_{\mathrm{m}}$ represent the parameter estimates for the impact of the three antecedent constructs (i.e., waiting time, environmental quality and interactional quality) on the mediating variable (waiting experience), $b_{m}$ represents the parameter estimate for the impact of the mediating variable on the dependent variable (i.e., the impact of waiting experience on overall experience). While $\mathrm{g}_{\mathrm{m}}$ represents the parameter estimates for the direct effect of the three antecedent constructs on overall experience, additional parameter estimates for the indirect effect (through the mediation of waiting experience) of the antecedent constructs on overall experience are obtained by multiplying the $a_{m}$ and $b_{m}$. Table 3 reports the standardized parameter estimates for Model 1,2, and 3.

In what follows, we first discuss the parameter estimates in Model 1 (baseline model that does not take the choice of an actor-oriented service package into consideration) and subsequently the parameter estimates in Model 2 and 3 (models that take the choice of actor-oriented service packages into consideration, respectively single service provider packages and multiple service provider packages).

Insert Table 3 about here

\section{Model 1: customer experience formation process in relation to the focal service provider}

Model 1 serves as baseline model, which provides insight into the customer experience formation in relation to the focal service provider without taking the service package choice into consideration. As shown in Table 3, the results demonstrate that waiting time has no significant 
direct effect on the overall experience $(\mathrm{g}=.06$, n.s.). In contrast, shorter waiting times were found to exert a positive impact on the waiting experience $(a=16)$, which on its turn, was found to enhance the overall experience $(b=.22)$. These results were qualified by a significant interaction effect $(\mathrm{axb}=.03)$, which demonstrates the indirect impact of waiting time on overall experience with the waiting experience as mediator. With regard to environmental and interactional quality, our results show that both drivers have a significant direct effect on overall experience ( $g=.27$ and $\mathrm{g}=.24$ respectively) and an indirect effect through the mediation of waiting experience. In sum, the baseline model (Model 1) shows full mediation (i.e., indirect effect only) for waiting time and partial mediation (i.e., direct and indirect effect) for environmental and interactional quality, as also visualized in Figure 2. Interestingly, none of the control variables were found to be significant, such that the $31 \%$ explained variance in overall experience can be mainly attributed to the three customer experience drivers and the waiting experience (see also Table 3).

\section{Model 2 and 3: contrasting single versus multiple service provider packages}

To gain insight into the impact of the choice of an actor-oriented service package on the customer experience formation process, we compare the parameter estimates for a single service provider package (Model 2) with a multiple service provider package (Model 3). Moreover, we performed additional significance tests to compare the magnitude of slopes of the obtained parameter estimates between both models. The results of these analyses are visually depicted in Figure 2. In what follows, we discuss the impact of waiting time (Hypothesis 1), and both environmental and interactional quality (Hypotheses $2 \mathrm{a}$ and $2 \mathrm{~b}$ ) on the overall experience, thereby taking the choice of actor-oriented service provider packages into consideration (single versus multiple service provider packages). 
Insert Figure 2 about here

With regard to waiting time, the results reported in Table 3 demonstrate that the impact of shorter waiting times on the overall experience is dependent on the choice of an actor-oriented service package. Specifically, waiting time has an indirect impact (through the mediation of the waiting experience) on the evaluation of overall experience in case of single service provider packages $(a x b=.04)($ Model 2). In contrast, we observe neither an indirect impact nor a direct impact of waiting time on overall experience when a multiple service provider package is chosen (Model 3), since the influence of waiting time on both waiting experience and overall experience is insignificant ( $\mathrm{a}=-.03$, n.s. and $\mathrm{g}=.09$, n.s.). Therefore, we conclude that the impact of waiting time on overall experience is weakened if a multiple service provider package - as opposed to a single service provider package - is chosen (see Figure 2). Hence, Hypothesis 1 is supported. Despite the support for Hypothesis 1, it is important to note that the impact of the waiting experience on overall experience is statistically different $(p<.01)$ and - as also shown in Figure 2 - substantially stronger for multiple service provider packages (Model 3; $b=.42$ ) compared with single service provider packages (Model 2; $\mathrm{b}=.16$ ). In sum, in case of multiple service provider packages (Model 3), only the subjective waiting experience is important, whereas the objective waiting time does not matter anymore.

With respect to environmental quality, Table 3 and Figure 2 demonstrate that the impact of environmental quality on overall experience is dependent on the service package choice. When a single service provider package is chosen (Model 2), we only observe a direct link from environmental quality to overall experience $(\mathrm{g}=.22)$, whereas both a direct and indirect effect (through the mediation of waiting experience) on overall experience are observed when a multiple service provider package is chosen (Model 3). As a result, the total effect of environmental quality 
on overall experience is much stronger (both direct and indirect effects) in multiple service provider packages (Model 3, $\mathrm{g}+\mathrm{axb}=.28+.09=.37$ ) than in single service provider packages (Model 2, $\mathrm{g}+\mathrm{axb}=.22+.02=.24)$. Hence, Hypothesis $2 \mathrm{a}$ is rejected (opposite effect).

Regarding interactional quality, Table 3 and Figure 2 show both a direct and indirect influence through waiting experience on overall experience when a single service provider package is chosen (Model 2), which is in line with the baseline model (Model 1). In case a multiple service provider package is selected (Model 3), the direct impact of interactional quality on overall experience disappears ( $\mathrm{g}=-.02$,n.s.), despite the fact that the relationship between waiting experience and overall experience is statistically stronger than in situations where a single service provider package is chosen (see also Figure 2). All taken together, however, the total effect of interactional quality on overall experience is much stronger (both direct and indirect effects) in single service provider packages (Model $2, \mathrm{~g}+\mathrm{axb}=.35+.03=.38$ ) than in multiple service provider packages (Model 3, $\mathrm{g}+\mathrm{axb}=-.02+.12=.10$ ). Hence, Hypothesis $2 \mathrm{~b}$ is supported.

Finally, the choice of an actor-oriented service package provides insight into waiting experiences and overall experiences, especially in situations where a multiple service provider package is selected (Model 3). More particularly, the R-squares between Model 1 and Model 3 increase from 16. to .28 for waiting experience, and from .31 to .39 for overall experience (see also Table 3).

\section{POST-HOC ANALYSIS}

To gain a more in-depth understanding of the impact of multiple service provider packages on the customer experience formation in relation to the focal service provider, the multiple service provider packages were further explored. Further analysis of the patient observation data revealed that service components in multiple service provider packages are produced at different times and 
locations. Extant research confirms that customers engage with service providers at different times and locations, which are seen as important proximity dimensions (Knoben and Oerlemans, 2006). The time distance from the goal state does affect the waiting experience and the overall evaluation of a service (Lewin, 1943; Holmqvist et al., 2015). More specifically, service providers may produce service components on the same day as the focal service provider (high time proximity) or one or more days before or after customers get a service component from the focal service provider (low time proximity). Likewise, service providers can produce service components next to the CDU (high location proximity) or at another location (low location proximity). Consequently, we argue that the operational aspects of multiple service provider packages - time and location proximity - impact the formation of the customer experience in relation to the focal service provider. Additional discussions with the head nurses and physicians at the CDUs confirmed that time and location proximity are important characteristics of multiple service provider packages.

Based upon the aforementioned evidence, we investigate the impact of time and location proximity in multiple service provider packages on the customer experience formation process in relation to the focal service provider. Here, time proximity and location proximity are defined as the degree to which service components of multiple providers are produced on a time and location deviating from the day and the location of the service components produced by the focal service provider. Based upon the information about service providers and time stamps in the patient observation templates (see Table 1), we coded time and location proximity as either 0 (low proximity of time/location) or 1 (high proximity of time/location) and linked these data to survey data of customers opting for multiple service provider packages $(n=123)$. Since cross-tab analyses demonstrate that the combination of high time proximity and low location proximity did not occur, we identified three types of multiple service provider packages: (a) multiple service provider 
packages characterized by high time-high location proximity $(n=42-34.2 \%)$, (b) multiple service provider packages characterized by low time-high location proximity $(n=8-39.0 \%)$, and (c) multiple service provider packages with service providers characterized by low time-low location proximity $(n=33-26.8 \%)$.

To understand the impact of these three types of multiple service provider packages on the formation of the customer experience in relation to the focal service provider, we used a hierarchical Bayes model. As customers were not randomly assigned to the type of multiple service provider packages, we controlled for customer heterogeneity. A multinomial logistic regression with the three types of multiple service provider packages as dependent variable and the six controls as independent variables results in a high explanatory power (Nagelkerke $\mathrm{R}^{2}=59 \%$ ). Again, the choice of the customer can be considered to have random differences, and therefore selection bias is not a confounding factor in our analysis (Ho et al., 2017).

\section{Model 3a, 3b and 3c: contrasting three types of multiple service provider packages}

We reran the forementioned Bayesian mediation model for the customer experience formation process for the three types of multiple provider service packages (i.e. high time-high location proximity, low time-high location proximity and low time-low location proximity). The standardized parameter estimates of these analyses are reported in respectively Model 3a, $3 \mathrm{~b}$ and 3c in Table 3. To increase the comprehensibility, the results are also visualized in Figure 2.

With regard to multiple service provider packages characterized by high time-high location proximity (Model 3a), we discern only a significant positive relationship between waiting experience and the overall experience in relation to the focal service providers $(\beta=.43)$. This relationship is also significant for multiple service provider packages characterized by low timehigh location proximity (Model $3 \mathrm{~b}, \beta=.51$ ), but the waiting experience of these customers also depends on the environmental and interactional quality (respectively $\mathrm{a}=.29$ and $\mathrm{a}=.44$ ). For multiple 
service provider packages characterized by low time-low location proximity (Model 3c), we observe that environmental and interactional quality both have a direct impact on the overall experience ( $g=.44$ and $g=.35)$ and that interactional quality also positively impacts the waiting experience $(a=.37)$.

\section{DISCUSSION}

\section{Theoretical contribution}

The present research contributes to the service modularity literature by proposing a new logic for decomposing services. Specifically, this research shows that services cannot only be decomposed based upon what services are delivered (outcome-oriented logic) and/or the sequence in which services are delivered (process-oriented logic), as suggested in the review study of Eissens-van der Laan et al. (2016). Indeed, services can also be decomposed based upon the actors who produce service components, which is an actor-oriented logic for modularizing services. Although a couple of studies have implicitly recognized this service modularity logic (e.g., De Blok et al., 2014; Tax et al., 2013; Brax et al., 2017), the present research contributes to the service modularity literature by explicating the importance of actor-oriented service modularity in multiprovider contexts and empirically investigating its implications for the formation of customer experiences in relation to the focal service provider.

Interestingly, the present research demonstrates that actor-oriented service modularity has an impact on the way in which customer experiences with the focal service provider are formed, thereby providing insight in the performance implications of (modular) service design decisions (e.g., Zomerdijk and de Vries, 2007; Ponsignon et al., 2011; Brax et al., 2017). Specifically, the research results demonstrate that interactional and/or environmental quality in multiple service provider packages can act as fillers and/or distractors that improve customers' appraisal of the wait 
more than the actual waiting time. Although this evidence seems to mirror the psychology of waiting discussed in previous research (Lim et al., 2015; Maister, 1984; Voorhees et al., 2009), the waiting experience is a more important driver of the overall experience in relation to the focal service provider in case of multiple service provider packages than in single service provider packages (i.e., Model 3 versus Model 2). Moreover, the impact of actual waiting time on the overall experience in relation to the focal service provider completely disappears if multiple service provider packages - as opposed to single service provider packages - are chosen (i.e., Model 2 versus Model 3). This evidence suggests that the service package choice has implications for the psychology of waiting.

In a similar vein, the impact of interactional quality on the overall experience in relation to the focal service provider is weaker for multiple service provider packages than for single service provider packages (i.e., Model 3 versus Model 2). Building upon attribution theory (Van Vaerenbergh et al., 2014), it is conceivable that interactions with other service providing entities deduce customers' attention away from the interactional quality in relation to the focal service provider. Here, the quality of interactions with employees involved in the delivery of service components associated with the focal service provider may get influenced by the interactional quality related to other service providing entities.

Further support for the aforementioned explanation of how other service providing entities affect customer experience formation in relation to the focal service provider stems from the observation that the impact of interactional quality on the overall experience in relation to the focal service provider disappears when the distance among service providing entities is minimized in terms of time and space (i.e., Model 3a). Moreover, high time and location proximity among service providing entities also diverts customers' attention from the quality of the physical environment in which the service components of the focal service provider are offered. In contrast 
with the other service provider packages, the overall experience with the focal service provider only depends on the waiting experience and the impact of environmental quality - which is emphasized in the servicescape literature (Bitner et al., 1992) - disappears. It is conceivable that exchanges with another service provider in multiple service provider packages characterized by high time-high location proximity have become a filler, which extends the waiting psychology literature (Maister, 1984).

Taken together, this research demonstrates that not only the choice for single versus multiple service provider packages affect customer experience formation in relation to the focal service provider, but also time and location proximity in multiple service provider packages. Indeed, time and location proximity in multiple service provider packages increased the extent to which customers were distracted when evaluating the customer experience with the focal service provider. Although the focal service provider did not decompose services based upon the time and location proximity of multiple service provider in the present case, it is not inconceivable that these dimensions are also taken into consideration when implementing actor-oriented service modularization. Since time and location proximity among service providing entities relates to not only who is involved in the delivery of service components (actor-oriented logic) but also how service components are delivered (process-oriented logic), this research suggests - in line with the review study of Eissens-van der Laan et al. (2016) - that different service modularity logics can be combined. Figure 1 depicts the combinations of service modularity logics.

\section{Limitations and future research directions}

As this is one of the first studies to investigate service modularity from an actor-oriented logic, this research focused on a very specific type of actor-oriented service modularity, namely decomposing services based upon the involvement of single versus multiple service providing 
entities. It goes without saying that service providers have multiple opportunities for actor-oriented service modularization. Service providers can, for instance, decompose services based upon the number of service providing entities (e.g., service package with one versus two service providers versus three service providers) or the exact constellation of service providing entities (e.g., packages with the CDU and the specific general practitioner, packages with the CDU and the specific polyclinic). Future research might further explore the different options for modularizing services in an actor-oriented way along with possible combinations with process-oriented or outcome-oriented service modularity.

Next, this research centered on the implications of actor-oriented service modularity on the customer experience formation with the focal service provider. Although several researchers contend that generating better customer experiences is of upmost importance for service providers (Lemon and Verhoef, 2016), the efficiency gains associated with actor-oriented service modularity also deserve further investigation. Moreover, future research may move away from a focal service provider perspective and look at the performance implications from a customer or network/system perspective (Avlonitis and Hsuan, 2017). A customer perspective on the performance implications of service modularity may involve the overall service experience (rather than the experience with only the focal service provider), thereby focusing on the degree to which customers' needs are met or customer well-being. If a network/system perspective is adopted, researchers need to investigate the multitude of performance implications of actor-oriented modularity for different service providing entities involved in the delivery of service components.

Building upon the importance of rapid and effective coordination and communication among service providing entities in a multi-provider context (De Blok et al., 2014; Brax et al., 2017), future research may also investigate the service architecture of the interfaces (i.e., how two components or service providers in a modular system mutually interact). Indeed, interfaces 
remained an underexposed issue in the present research, although this may also affect the way in which customer experiences are formed and even other performance implications.

Finally, the present research was carried out in the context of high-contact services, which may decrease the generalizability to other types of services. In case of online services, for instance, interactional quality matters most when service failures occur ( $\mathrm{Li}, 2015)$. As such, its impact on the customer experience may be different when comparing single versus multiple service providing packages. Moreover, the specific types of multiple service provider packages - which were identified in the post-hoc analysis - are strongly related to the type of service. Location proximity, for instance, might be less relevant in the context of very specialized services where customers only have a limited choice in service providers.

\section{Managerial implications}

This research has important implications for managers engaged in either modularizing services or (re)designing services. With regard to service modularization, this research identified a new logic for decomposing services: the actor-oriented logic. This logic may be used solely or in combination with a process- and/or outcome-oriented logic. Beyond paving the way for new service modularization options by proposing a new decomposition logic, this research also calls for careful reflection about investments in experience drivers when opting for service modularization. Multiple service provider packages, for instance, render customers less sensitive to the actual waiting time than single service provider packages. As such, actions directed towards reducing the length of a wait - such as queue management based on principles of queuing theory and simulation (Weiss and Tucker, 2018) - are less effective for customers opting for multiple service provider packages than for those opting for single service provider packages. The same goes for actions directed towards increasing the interactional quality (e.g. interpersonal skills 
training) and environmental quality (e.g., infrastructural investments), as the impact of these experience drivers differs for various service packages.

As not all experience drivers are equally important in all service packages, practitioners may either align their investments with the most prominent experience drivers across service packages or change the way in which service packages are constituted. For instance, barriers for infrastructural investments may urge service providers to remove service packages where environmental quality is crucial for the formation of the customer experience with the focal service provider. Instead of removing service packages, practitioners may also decide to change the decomposition logic. This may, for instance, happen when practitioners are not willing or able to deal with the heterogeneity in terms of customer experience formation caused by single versus multiple service provider packages.

Finally, the impact of single versus multiple service provider packages on customer experience formation also has implications for practitioners engaged in (re-)designing services. Specifically, the present research calls for careful reflection about allowing customers or employees to involve other service providing entities in service delivery processes, as these actors - along with their time and location proximity characteristics - may affect the formation of customer experiences in relation to the focal service provider. This issue is particularly relevant, as service providers increasingly recognize that services are delivered in multi service provider networks (Tax et al., 2013; Brax et al.,2017). 


\section{REFERENCES}

Albrecht, C.M., Hattula, S., Bornemann, T., \& Hoyer, W.D. 2016. Customer response to interactional service experience: The role of interaction environment. Journal of Service Management, 27 (5): 704-729.

Allen, A.M., Brady, M.K., Robinson, S.G., \& Voorhees, C.M. 2015. One firm's loss is another's gain: capitalizing on other firms' service failures. Journal of the Academy of Marketing Science, 43(5): 648-662.

Allon, G. \& Federgruen, A. 2007. Competition in service industries, Operations Research, 55(1): 37-55.

Anderson, N.H. 1981. Foundations of information integration theory. New York: Academic Press.

Avlonitis, V., \& Hsuan, J. 2017. Exploring modularity in services: cases from tourism. International Journal of Operations \& Production Management, 37(6): 771-790.

Baker, J., \& Cameron, M. 1996. The effects of the service environment on affect and consumer perception of waiting time: An integrative review and research propositions. Journal of the Academy of Marketing Science, 24(4): 338.

Beltagui, A., Candi, M., \& Riedel, J.C. 2016. Setting the stage for service experience: design strategies for functional services. Journal of Service Management, 27(5): 751-772.

Berry, L.L., \& Bendapudi, N. 2007. Health care: a fertile field for service research. Journal of Service Research, 10(2): 111-122.

Bitner, M.J. 1992. Servicescapes: The impact of physical surroundings on customers and employees. Journal of Marketing, 56(2): 57-71.

Bitran, G.R., Ferrer, J.C., \& Rocha e Oliveira, P. 2008. Om forum-managing customer experiences: perspectives on the temporal aspects of service encounters. Manufacturing $\boldsymbol{\&}$ Service Operations Management, 10(1): 61-83.

Brax, S.A., Bask, A., Hsuan, J., \& Voss, C. 2017. Service modularity and architecture-an overview and research agenda. International Journal of Operations \& Production Management, 37(6): 686-702.

Carr, T., Teucher, U.C., \& Casson, A.G. 2014. Time while waiting: Patients' experiences of scheduled surgery. Qualitative Health Research, 24(12): 1673-1685.

Clucas, C. 2016. Cancer patients' respect experiences in relation to perceived communication behaviours from hospital staff: analysis of the 2012-2013 National Cancer Patient Experience Survey. Supportive Care in Cancer, 24(4): 1719-1728.

Dagger, T.S., Sweeney, J.C., \& Johnson, L.W. 2007. A hierarchical model of health service quality: scale development and investigation of an integrated model. Journal of Service Research, 10(2): 123-142.

De Blok, C., Meijboom, B., Luijkx, K., Schols, J., \& Schroeder, R. 2014. Interfaces in service modularity: a typology developed in modular health care provision. Journal of Operations Management, 32(4), 175-189.

Durrande-Moreau, A., \& Usunier, J.C. 1999. Time styles and the waiting experience: an exploratory study. Journal of Service Research, 2(2): 173-186.

Eissens-van der Laan, M., Broekhuis, M., van Offenbeek, M., \& Ahaus, K. 2016. Service decomposition: a conceptual analysis of modularizing services. International Journal of Operations \& Production Management, 36(3): 308-331. 
Fornell, C., \& Larcker, D.F. 1981. Evaluating structural equation models with unobservable variables and measurement error. Journal of Marketing Research, 18(1): 39-50.

Gardial, S.F., Clemons, D.S., Woodruff, R.B., Schumann, D.W., \& Burns, M.J. 1994. Comparing consumers' recall of prepurchase and postpurchase product evaluation experiences. Journal of Consumer Research, 20(4), 548-560.

Heider, F. 1958. The Psychology of Interpersonal Relations. New York: John Wiley.

Ho, T.H., Lim, N., Reza, S., \& Xia, X. 2017. OM forum-Causal inference models in operations management. Manufacturing \& Service Operations Management, 19(4): 509-525.

Holmqvist, J., Guest, D., \& Grönroos, C. 2015. The role of psychological distance in value creation. Management Decision, 53(7): 1430-1451.

Hox, J.J., Moerbeek, M., \& van de Schoot, R. 2010. Multilevel analysis: Techniques and applications. New York: Routledge.

Hui, M.K., \& Tse, D.K. 1996. What to tell consumers in waits of different lengths: An integrative model of service evaluation. Journal of Marketing, 60(2): 81-90.

Kranzbühler, A.M., Kleijnen, M.H., Morgan, R.E., \& Teerling, M. 2018. The multilevel nature of customer experience research: an integrative review and research agenda. International Journal of Management Reviews, 20(2), 433-456.

Keiningham, T.L., Rust, R.T., Lariviere, B., Aksoy, L., \& Williams, L. 2018. A roadmap for driving customer word-of-mouth. Journal of Service Management, 29(1): 2-38.

Knoben, J., \& Oerlemans, L.A. 2006. Proximity and inter-organizational collaboration: A literature review. International Journal of Management Reviews, 8(2):71-89.

Kumar, P., \& Krishnamurthy, P. 2008. The impact of service-time uncertainty and anticipated congestion on customers' waiting-time decisions. Journal of Service Research, 10(3): 282292.

Lemke, F., Clark, M., \& Wilson, H. 2011. Customer experience quality: an exploration in business and consumer contexts using repertory grid technique. Journal of the Academy of Marketing Science, 39(6): 846-869.

Lemon, K.N., \& Verhoef, P.C. 2016. Understanding customer experience throughout the customer journey. Journal of Marketing, 80(6): 69-96.

Lewin, K. 1943. Defining the 'field at a given time.' Psychological Review, 50(3): 292-310.

Li, C.Y. 2015. Switching barriers and customer retention: Why customers dissatisfied with online service recovery remain loyal. Journal of Service Theory and Practice, 25(4): 370-393.

Lim, E.A.C., Kum, D., \& Lee, Y.H. 2015. Understanding how changes within service experiences impact prospective vs. retrospective time judgments. Journal of the Academy of Marketing Science, 43(6): 730-745.

Maister, D.H. 1984. The Psychology of Waiting Lines. Boston: Harvard Business School.

McColl-Kennedy, J.R., Vargo, S.L., Dagger, T.S., Sweeney, J.C., \& Kasteren, Y.V. 2012. Health care customer value cocreation practice styles. Journal of Service Research, 15(4): 370389.

Netemeyer, R.G., Bearden, W.O., \& Sharma, S. 2003. Scaling procedures: Issues and applications: Thousand Oaks: Sage Publications.

Patterson, B.M., Eskildsen, S.M., Clement, R.C., Lin, F.C., Olcott, C.W., Del Gaizo, D.J., \& Tennant, J.N. 2017. Patient satisfaction is associated with time with provider but not clinic wait time among orthopedic patients. Orthopedics, 40(1), 43-48.

Patrício, L., Fisk, R.P., Falcão e Cunha, J., \& Constantine, L. 2011. Multilevel service design: from customer value constellation to service experience blueprinting. Journal of Service Research, 14(2), 180-200. 
Pekkarinen, S., \& Ulkuniemi, P. 2008. Modularity in developing business services by platform approach. The International Journal of Logistics Management, 19(1): 84-103.

Peters, V.J.T., Meijboom, B.R., \& de Vries, E. 2018. Interfaces in service modularity: a scoping review. International Journal of Production Research, 56(20): 6591-6606.

Podsakoff, P.M., MacKenzie, S.B., Lee, J.Y., \& Podsakoff, N.P. 2003. Common method biases in behavioral research: A critical review of the literature and recommended remedies. Journal of Applied Psychology, 88(5): 879-903.

Ponsignon, F., Smart, P.A., \& Maull, R.S. 2011. Service delivery system design: characteristics and contingencies. International Journal of Operations \& Production Management, 31(3): 324-349.

Pruyn, A., \& Smidts, A. 1998. Effects of waiting on the satisfaction with the service: Beyond objective time measures. International Journal of Research in Marketing, 15(4): 321334.

Pullman, M.E., \& Gross, M.A. 2004. Ability of experience design elements to elicit emotions and loyalty behaviors. Decision sciences, 35(3): 551-578.

Roth, A.V., \& Menor, L.J. 2003. Insights into service operations management: a research agenda. Production and Operations management, 12(2): 145-164.

Simonin, B.L., \& Ruth, J.A. 1998. Is a company known by the company it keeps? Assessing the spillover effects of brand alliances on consumer brand attitudes. Journal of Marketing Research, 35(1): 30-42.

Tax, S.S., McCutcheon, D., \& Wilkinson, I.F. 2013. The service delivery network (SDN) a customer-centric perspective of the customer journey. Journal of Service Research, 16(4): 454-470.

Taylor, S. (1994). The effects of filled waiting time and service provider control over the delay on evaluations of service. Journal of the Academy of Marketing Science, 23(1): 38-48.

Tuunanen, T., Bask, A., \& Merisalo-Rantanen, H. 2012. Typology for modular service design: review of literature. International Journal of Service Science, Management, Engineering, and Technology, 3(3), 99-112.

Van Riel, A.C., Semeijn, J., Ribbink, D., \& Bomert-Peters, Y. 2012. Waiting for service at the checkout: Negative emotional responses, store image and overall satisfaction. Journal of Service Management, 23(2): 144-169.

Van Vaerenbergh, Y., Orsingher, C., Vermeir, I., \& Larivière, B. 2014. A meta-analysis of relationships linking service failure attributions to customer outcomes. Journal of Service Research, 17(4): 381-398.

Verleye, K. 2015. The co-creation experience from the customer perspective: its measurement and determinants. Journal of Service Management, 26(2): 321-342.

Verleye, K., Gemmel, P., \& Rangarajan, D. 2014. Managing engagement behaviors in a network of customers and stakeholders: Evidence from the nursing home sector. Journal of Service Research, 17(1):68-84.

Voorhees, C.M., Baker, J., Bourdeau, B.L., Brocato, E.D. \& Cronin Jr, J.J. 2009. It depends: Moderating the relationships among perceived waiting time, anger, and regret. Journal of Service Research, 12(2): 138-155.

Weiss, E.N., \& Tucker, C. 2018. Queue management: Elimination, expectation, and enhancement. Business Horizons, 61(5): 671-678.

Wikner, J., Yang, B., Yang, Y., \& Williams, S.J. 2017. Decoupling thinking in service operations: a case in healthcare delivery system design. Production Planning \& Control, 28(5): 387397. 
Yuan, Y., \& MacKinnon, D.P. 2009. Bayesian mediation analysis. Psychological Methods, 14(4): 301-322.

Zomerdijk, L.G., \& de Vries, J. 2007. Structuring front office and back office work in service delivery systems: an empirical study of three design decisions. International Journal of Operations \& Production Management, 27(1): 108-131. 


\section{TABLE 1}

\section{Coding and calculation of the patient observation data}

\begin{tabular}{lll}
\hline Variables & Operationalization & Source \\
\hline $\begin{array}{l}\text { Type of actor- } \\
\text { oriented service } \\
\text { package }\end{array}$ & Single service provider package (0) or multiple service & $\begin{array}{l}\text { Description of service providing } \\
\text { provider package (1) }\end{array}$ \\
$\begin{array}{l}\text { template } \\
\text { tities the patient observation }\end{array}$
\end{tabular}

Waiting time Calculation of the difference between the time of the Time stamps for all service delivery of the first service component (e.g., patient components in the patient registration) and the last service component (e.g., observation template therapy) at the $\mathrm{CDU}$

Number of CDU Number of service components delivered at the CDU service before the delivery of the last service component components

CDU CDU coded as CDU1 (0) or CDU2 (1)

Description of service providing entities in combination with time stamps for all service components in the patient observation template

Name of the CDU reported in the patient observation template

Fellow customer

Room number coded as no fellow customer (0) or presence of fellow customer (1)

Patient room number reported in the patient observation template in combination with data about room occupancy rate at the $\mathrm{CDU}$

Treatment response

Location proximity

Time proximity
Remarks coded as no side effects ( 0 ) or the occurrence of side effects (1)

Service providers other than the focal service provider coded as either producing service components next to the CDU ( $1=$ high location proximity) or not $(0=$ low location proximity)

Service providers other than the focal service provider Description of service providing coded as either producing service components on the entities in combination with time same day $(1=$ high time proximity) or not $(0=$ low time stamps for all service components proximity) in the patient observation template

Note. CDU=Cancer Daycare Unit. CDU1 - which treats on average 30 patients per day - focuses on oncology patients from a wide range of medical disciplines including gynecology, head and neck, neurology, skin diseases, ear nose throat, urology, etc. CDU $2-$ which treats on average 42 patients per day - focuses on patients with hematological, pneumological, and gastrointestinal problems. 


\section{TABLE 2}

\section{Results confirmatory factor analysis}

Construct and Items

Factor Loadings

Waiting experience (adapted from Hui and Tse 1996)

$M=5.03, S D=1.52, C R=.70$, Cronbach's Alpha $=.89, A V E=.81$

I experience the time before the start of the treatment as very unpleasant. (reversed) 93

I experience the time before the start of the treatment as unacceptable. (reversed) $\quad .65$

I experience the time before the start of the treatment as long. (reversed) .83

Environmental quality (adapted from Dagger et al. 2007)

$M=4.92, S D=1.27, C R=.77$, Cronbach's Alpha $=.94, A V E=.86$

I believe the physical environment at the CDU is excellent.

I am impressed with the quality of the CDU's physical environment.

$\begin{array}{ll}\text { The physical environment at the CDU is of a high standard. } & .82\end{array}$

Interactional quality (adapted from Dagger et al. 2007)

$M=5.94, S D=.73, C R=.58$, Cronbach's Alpha $=.92, A V E=.71$

The staff at the CDU always listen to what I have to say. $\quad .70$

The CDU's staff treat me as an individual and not just a number. 52

$\begin{array}{ll}\text { I feel the staff at the CDU understand my needs. } & .78\end{array}$

The staff at the CDU are concerned about my well-being.

I always get personalized attention from the staff at the CDU. 65

I find it easy to discuss things with the staff at the CDU.

The staff at the CDU explain things in a way that I can understand. 72

The staff at the CDU are willing to answer my questions. $\quad .71$

I believe the staff at the CDU care about me. $\quad .75$

Overall experience (adapted from Verleye 2015)

$M=6.02, S D=.97, C R=.62$, Cronbach's Alpha $=.90, A V E=.74$

$\begin{array}{ll}\text { Dissatisfactory - Satisfactory } & .65\end{array}$

$\begin{array}{ll}\text { Negative }- \text { Positive } & .79\end{array}$

$\begin{array}{lr}\text { Poor - Excellent } & .84\end{array}$

Disappointing - Delightful $\quad .65$

Note. $\mathrm{CDU}=$ cancer daycare unit; $\mathrm{M}=$ mean construct score (unweighted); $\mathrm{SD}=$ standard deviation; $\mathrm{CR}=$ composite reliability; the diagonal (in italics) shows the square root of the AVE for each construct; the off-diagonal numbers represent the correlations among constructs; ${ }^{*} \mathrm{p}<.05$. 
TABLE 3

Standardized parameter estimates for Bayesian models

\begin{tabular}{|c|c|c|c|c|c|c|c|c|c|c|c|c|}
\hline & \multicolumn{2}{|c|}{$\begin{array}{r}\text { Model } 1 \\
\text { baseline model }\end{array}$} & \multicolumn{2}{|c|}{$\begin{array}{r}\text { Model } 2 \text { single } \\
\text { service provider } \\
\text { package }\end{array}$} & \multicolumn{2}{|c|}{$\begin{array}{r}\text { Model } 3 \text { multiple } \\
\text { service provider } \\
\text { package }\end{array}$} & \multicolumn{2}{|c|}{$\begin{array}{r}\text { Model 3a high time- } \\
\text { high location } \\
\text { proximity (i.e., the } \\
\text { same day next to the } \\
\text { CDU) }\end{array}$} & \multicolumn{2}{|c|}{$\begin{array}{r}\text { Model 3b low time- } \\
\text { high location } \\
\text { proximity (i.e., } \\
\text { another day next to } \\
\text { the CDU) }\end{array}$} & \multicolumn{2}{|c|}{$\begin{array}{r}\text { Model 3c low time- } \\
\text { low location } \\
\text { proximity (i.e., } \\
\text { another day at } \\
\text { another location) }\end{array}$} \\
\hline & WX & $\mathrm{OX}$ & WX & OX & WX & OX & WX & OX & WX & OX & WX & OX \\
\hline Intercept & .81 & $2.51 *$ & .99 & $1.63 *$ & -.03 & $3.90 *$ & 1.47 & $3.51 *$ & -.48 & $3.47 *$ & -2.18 & -1.07 \\
\hline \multicolumn{13}{|l|}{ Drivers } \\
\hline Waiting time (reversed) & $.16^{*}$ & .06 & $.23 *$ & .07 & -.03 & .09 & .11 & .09 & -.10 & .10 & -.05 & .21 \\
\hline Environmental quality & $.15^{*}$ & $.27 *$ & .12 & $.22 *$ & $.22 *$ & $.28^{*}$ & .26 & .29 & $.29 *$ & .19 & .07 & $.44^{*}$ \\
\hline Interactional quality & $.24 *$ & $.24 *$ & $.20 *$ & $.35^{*}$ & $.29 *$ & -.02 & .02 & -.15 & $.44^{*}$ & -.09 & $.37 *$ & $.35^{*}$ \\
\hline WX & & $.22 *$ & & $.16^{*}$ & & $.42 *$ & & $.43 *$ & & $.51^{*}$ & & .10 \\
\hline \multicolumn{13}{|l|}{ Interaction } \\
\hline Waiting time $\mathrm{x} W X$ & & $.03 *$ & & $.04 *$ & & -.01 & & .05 & & -.05 & & -.01 \\
\hline $\begin{array}{l}\text { Environmental quality } \mathrm{x} \\
\mathrm{WX}\end{array}$ & & $.03 *$ & & .02 & & $.09 *$ & & .11 & & $.15^{*}$ & & .01 \\
\hline Interactional quality $\mathrm{x}$ WX & & $.05^{*}$ & & $.03 *$ & & $.12 *$ & & .01 & & $.22 *$ & & .04 \\
\hline \multicolumn{13}{|l|}{ Control variables } \\
\hline Age & -.01 & -.10 & .13 & -.08 & -.17 & -.04 & -.18 & -.09 & -.24 & .04 & -.01 & -.15 \\
\hline Employment situation & .04 & -.04 & .14 & -.04 & -.01 & -.01 & -.01 & -.12 & -.08 & .14 & .05 & -.04 \\
\hline $\mathrm{CDU}$ & .05 & -.01 & .07 & -.02 & -.04 & .03 & -.17 & .23 & .11 & -.11 & .09 & .01 \\
\hline $\begin{array}{l}\text { Number of service } \\
\text { components delivered at the } \\
\text { CDU }\end{array}$ & -.04 & -.00 & -.03 & .03 & -.01 & -.00 & .01 & .07 & -.14 & .01 & .03 & .27 \\
\hline Fellow customer & .01 & .00 & -.01 & .04 & .11 & -.12 & .07 & -.09 & .17 & -.17 & -.07 & -.06 \\
\hline Treatment response & -.02 & .02 & .05 & -.01 & -.15 & .04 & -.06 & .13 & -.03 & .04 & NA & NA \\
\hline$R^{2}$ & $.16^{*}$ & $.31 *$ & $.16^{*}$ & $.33 *$ & $.28 *$ & $.39 *$ & $.27^{*}$ & $.49 *$ & $.56^{*}$ & $.45^{*}$ & $.31 *$ & $.58 *$ \\
\hline
\end{tabular}




\section{FIGURE 1}

The service modularity decomposition logics

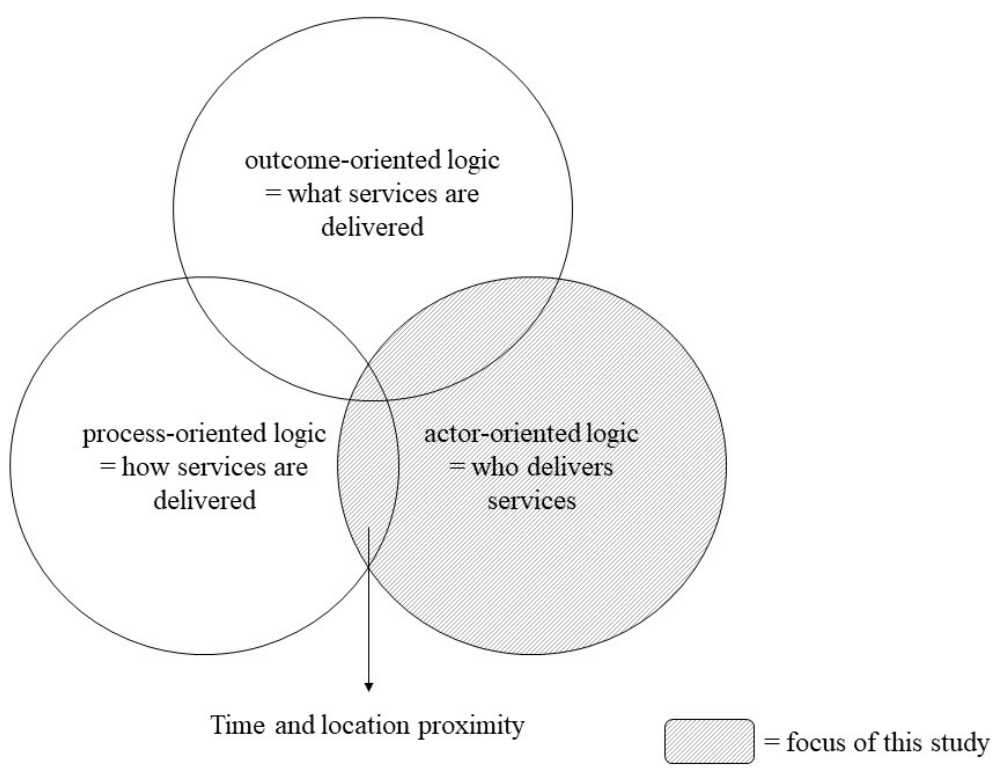




\section{FIGURE 2}

\section{Visualization of the results}

Baseline model without moderator

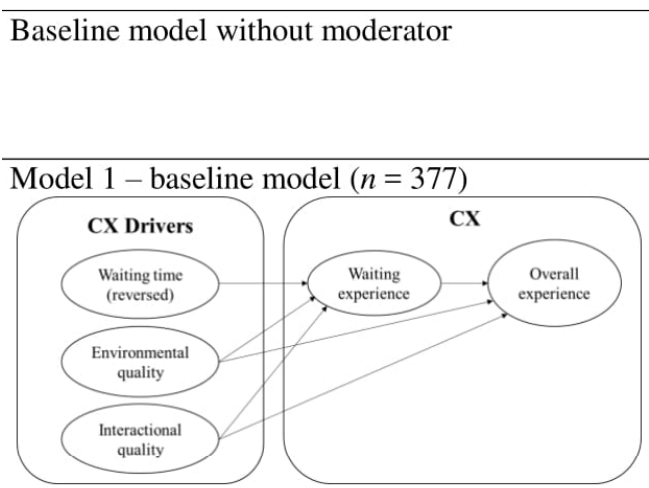

The type of actor-oriented service package as moderator (i.e., single versus multiple provider package)

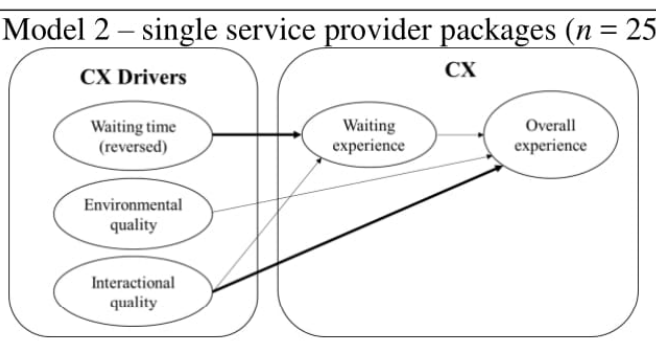

Model 3 - multiple service provider packages $(n=126)$

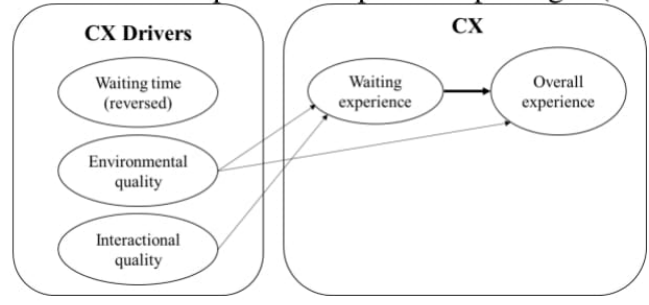

The type of multiple service provider package (i.e., variation by time and location proximity) as moderator

Model 3a - high time-high location proximity i.e., the same day next to the CDU $(n=42)$

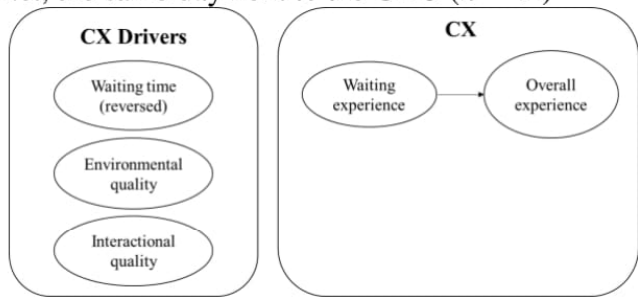

Model 3b-low time-high location proximity i.e., another day next to the CDU $(n=48)$

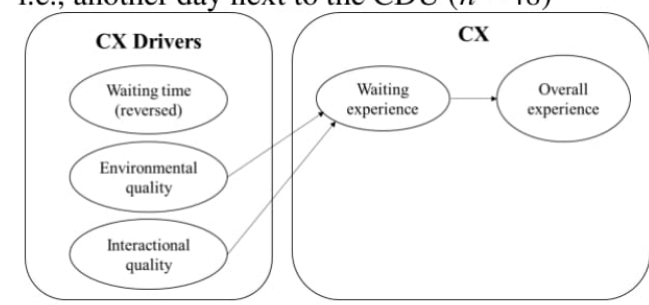

Model 3c - low time-low location proximity i.e., another day at another location $(n=33)$

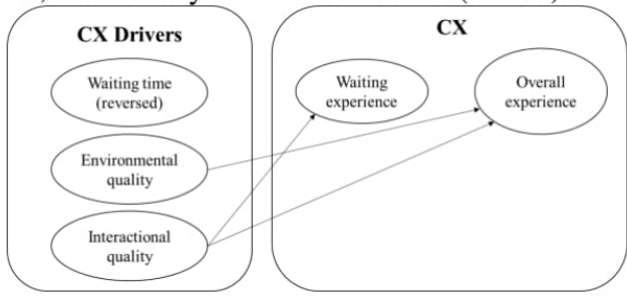

Note . $\mathrm{CX}=$ customer experience, arrows indicate significant positive relationship, thick arrows in Model 2 and 3 indicate that parameter estimate is significantly stronger than in respectively Model 3 and 2 . 